\title{
Clinicopathological Profile of Cervical Carcinoma: An Experience of Tertiary Care Cancer Centre
}

\author{
Manjit Kaur Rana $^{1}$, Karuna Singh ${ }^{1}$, M K Mahajan ${ }^{1}$, Amrit Pal Singh Rana ${ }^{2}$ \\ ${ }^{1}$ Advanced Cancer Institute (Affiliated with Baba Farid University of Health Sciences, Faridkot) Bathinda, India. ${ }^{2}$ GGS Medical
} College (Affiliated with Baba Farid University of Health Sciences, Faridkot).

\begin{abstract}
Context: Cervical cancer is a malignant neoplasm arising mainly in the transformation zone of the cervix. Cervical cancer is the second most common cancer among women worldwide after breast cancer. Squamous cell carcinoma and adenocarcinoma constitute the greatest burden, globally as well as in India. Aims: The current study was aimed to assess the histopathological profile and its correlation with clinical findings. Settings and Design: It was a retrospective analysis of the patients of cervical carcinoma. Methods and Material: The retrospective analysis of histopathological patterns of carcinoma cervix was done. A total of 120 cervical biopsies were received, amongst which 5 biopsies were chronic cervicitis, 9 were cervical intraepithelial neoplasia (CIN) and 106 cases were of carcinoma. Further histologic subtyping of cervical carcinoma was done and was correlated with clinical presentations and stage. The collected data were analysed. Statistical analysis used: Analysis of data was done for simple means and percentages. Results: The most common age group in carcinoma cervix was fifth and sixth decade with history of bleeding per vagina being the most common clinical presentation. Squamous cell carcinoma (SCC) was the most common variant, $\geq$ Stage III case constituted in majority and also showed poor prognosis.Conclusion: A majority of Indian women presented at later stages of cervical cancer, hence demanding the need of dedicated screening programes. Many variants present with different clinical findings especially as deep infiltrative growth patterns, hence histologic types should be kept in mind clinically while dealing with unfamiliar clinical presentations. In our experience most of the women presented in later stages and patients with $\geq$ stage III showed poor prognosis.
\end{abstract}

Keywords: Cervix- Adenocarcinoma- Glassy cell carcinoma- Carcinoma- Endophytic growth

Asian Pac J Cancer Care, 4 (3), 83-86

\section{Introduction}

Carcinoma cervix is the second most common cancer of women in India [1]. The incidence of carcinoma is $14 \%$ worldwide with $29.1 \%$ incidence in Asian countries [2]. It is the most common cause of death among women in the developing countries [3]. The discrepancies in the screening and treatment affects survival rate as the coverage of cervical cancer screening in the developing countries is $19 \%$ as compared to $63 \%$ in the developed countries [4]. The present study was conducted to determine the clinicopathological profile of cervical cancer patients attending tertiary care cancer hospitals in the developing country.
Submission Date: 02/05/2019 Acceptance Date: 04/02/2019

\section{Materials and Methods}

The retrospective analysis of 120 histopathological biopsy specimens received in the Department of Pathology for the evaluation of cervical lesions was done. All the biopsies were performed as outpatient door procedure except for the deeper biopsy which was performed in the minor operation theater. Various parameters such as age, presenting symptoms, duration of disease and staging of the disease were rechecked [5]. Histopathological types and subtypes were analyzed and correlated with clinical parameters.

Histopathological findings of preoperative biopsies were correlated with postoperative hysterectomy specimens in cases where the surgery was performed. 
The data obtained was analyzed.

\section{Results}

Amongst 120 cases, 106 cases were of carcinoma, 2 cases were of CIN II, 7 cases were of CIN III and 5 were of chronic cervicitis. The age group range for carcinoma varied from 33-80 years with mean age of $54.0 \pm 10.5$ years. Maximum number of patients was in fifth and sixth decade of life (Figure 1).

The most common clinical presentation in all histologic types of carcinoma was bleeding per vagina $(\mathrm{P} / \mathrm{V})($ Table 1).

The patients with age $>49$ years $(n=74,59.5 \pm 7.1)$ presented with late stage $(61.3 \%)$ in comparison with patients of age $<49$ years $(n=32,41.3 \pm 4.1$ years $)(52.1 \%)$. Only $2.8 \%$ cases were underwent Pap smear screening, rest of the cases presented with symptoms of carcinoma. Maximum number of cases presented with stage $\geq \mathrm{II}$ in all ages. The most common histopathological type detected was squamous cell carcinoma (SCC) $80.1 \%$, followed by 13.2\% adenocarcinoma (AD) (Figure 2).

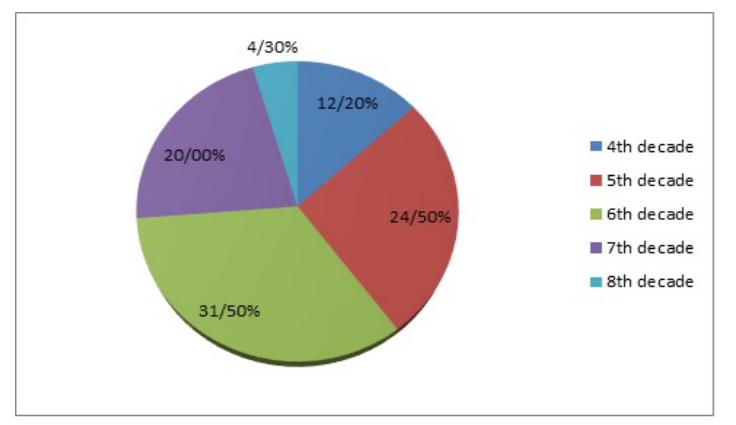

Figure 1. Agewise Distribution of Carcinoma Cervix Patients

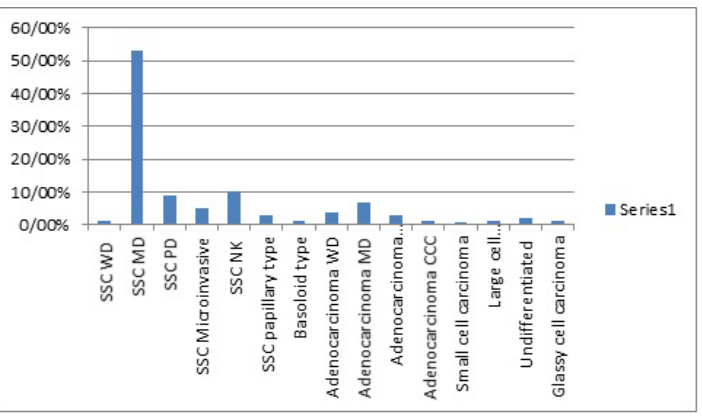

Figure 2. Histopathological Variants of Carcinoma a cervix

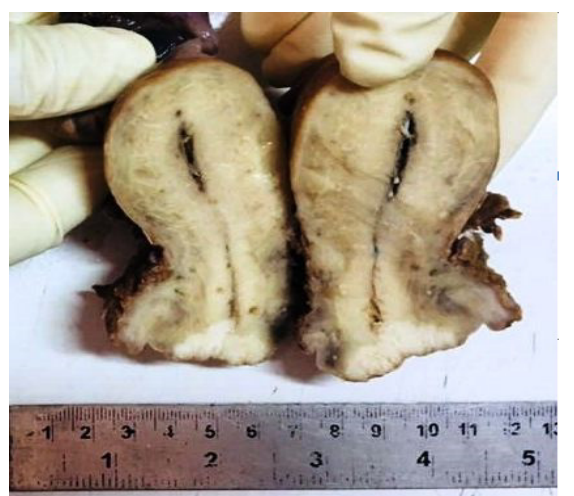

Figure 3. Gross Specimen of Adenocarcinoma Cervix

Clinical presentation and staging was compared with histopathologic types of carcinoma cervix (Tables 2,3).

One case of well differentiated carcinoma was treated case of carcinoma oesophagus.

\section{Discussion}

Cervical carcinoma can occur in of all ages of females, however its usual age at presentation is 35-55 years with the peak age for the incidence varying with populations. [6]. In current experience, the mean age was $54.0 \pm 10.5$ years with majority of cervical cancer cases diagnosed in the sixth decade of life followed by fifth decade. In India, the peak age for carcinoma cervix is 45-54 years, which is parallel to the rest of South Asia[7]. In our experience negligible number of cases $(2.8 \%)$ were presented through opportunistic screening. In various regions of India opportunistic screening varied from $0.0025 \%$ to $6.9 \%$ [8-9]. This may be the reason that majority of the cases in the current analysis presented in late stage $(80 \%)$. The early stages of carcinoma cervix are usually completely asymptomatic followed by bleeding $\mathrm{P} / \mathrm{V}$ (including intermenstrual, postmenopausal and post coital bleeding), but several times symptoms may be absent until the cancer is in its advanced stages [10]. In the western countries cervical cancer mortality has been reduced due to screening [4]. Late stage cervical cancer can present with weight and appetite loss, fatigue, pelvic pain, heavy bleeding $\mathrm{P} / \mathrm{V}$ and bone fracture in cases with metastasis. Our study also showed a majority of the patients presenting with late stage disease especially postmenopausal age group. The bleeding $\mathrm{P} / \mathrm{V}$ was seen in $81.1 \%$ as the most common finding followed by vaginal discharge in $7.5 \%$ and pain abdomen in $2.8 \%$ as seen in the study done by

Table 1. Symptomatic Profile of Cases with Cervical Lesions

\begin{tabular}{lcccc}
\hline Sr. no & Presenting symptoms & Total cases $(\%)$ & Maximum duration & Carcinoma found in cases $(\%)$ \\
\hline 1. & Bleeding & $95(79.1 \%)$ & $<6$ months & $86(90.5 \%)$ \\
2. & Discharge & $10(8.3 \%)$ & $>1$ year & $8(80 \%)$ \\
3. & Pain abdomen & $5(4.1 \%)$ & $>1$ year & $3(60 \%)$ \\
4. & Others & $1(0.8 \%)$ & $<6$ months & $1(100 \%)$ \\
5. & Recurrence (suspected) & $9(7.5 \%)$ & $<6$ months & $8(88.8 \%)$ \\
\hline
\end{tabular}


Table 2. Clinicopathological Correlation of Carcinoma Cervix

\begin{tabular}{lcccccc}
\hline Histologic type & ${ }^{1} \mathrm{~B}(\mathrm{P} / \mathrm{V})$ & ${ }^{2} \mathrm{D}(\mathrm{P} / \mathrm{V})$ & ${ }^{3} \mathrm{PA}$ & ${ }^{4} \mathrm{Os}$ & ${ }^{5} \mathrm{~A}$ & ${ }^{6} \mathrm{R}$ \\
\hline SCC & $90.5 \%$ & $3.5 \%$ & $1.1 \%$ & $0 \%$ & $2.3 \%$ & $5.8 \%$ \\
AD & $57.1 \%$ & $14.2 \%$ & $7.1 \%$ & $0 \%$ & $14.2 \%$ & $7.1 \%$ \\
${ }^{*}$ PDC & $75 \%$ & $0 \%$ & $0 \%$ & $0 \%$ & $25 \%$ & $0 \%$ \\
\$UDC & $50 \%$ & $0 \%$ & $0 \%$ & $50 \%$ & $0 \%$ & $0 \%$ \\
$* *$ CCC & $0 \%$ & $0 \%$ & $100 \%$ & $0 \%$ & $0 \%$ & $0 \%$ \\
\hline
\end{tabular}

${ }^{1}$ Bleeding $\mathrm{p} / \mathrm{v} ;{ }^{2}$ Discharge $\mathrm{p} / \mathrm{v} ;{ }^{3}$ Pain abdomen; ${ }^{4}$ Others; ${ }^{5}$ Associated findings; ${ }^{6}$ Recurrence; *Poorly differentiated carcinoma; $\$$ Undifferentiated carcinoma; $* *$ Clear cell carcinoma

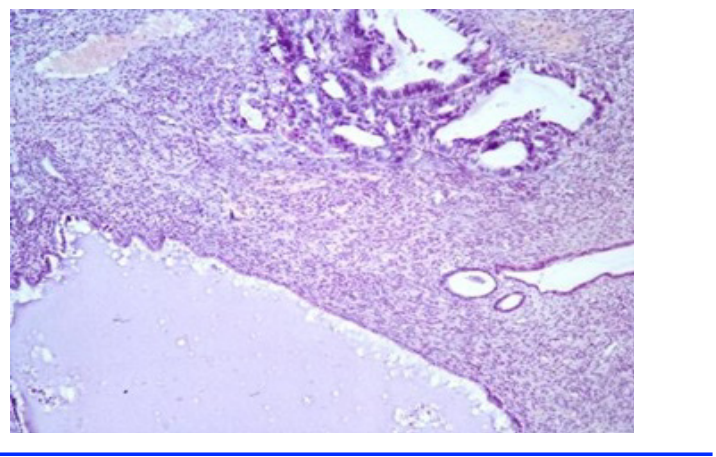

Figure 4. Adenocarcinoma Arising in the Polyp (H\&E stained section 20X)

Mukhtar et al [11-12,13]. The possibility of advanced disease presentation may be the social culture, and lack of awareness, as the maximum duration of symptoms varied from 6 months to years [14]. The most common type of carcinoma was SCC $(80.5 \%)$ and a wide spectrum of its subtypes was seen. Many studies done in the past showed SCC with its variants and AD as common histologic types of cervical carcinoma [13-15]. SCC was found to be the most common type constituting $58.2 \%$ of all the cervical carcinomas. Its different types of differentiation presented with bleeding $\mathrm{P} / \mathrm{V}$ in all except $0.5 \%$ cases of moderately differentiated (MD) SCC. The most common stage at presentation was stage III accounting for $41.6 \%$ in MD and $70 \%$ in poorly differentiated (PD) type whereas stage I was the common type in well differentiated (WD) SCC. There was no associated specific finding detected in all types except $10 \%$ cases SCC PD presenting with brain metastasis. SCC non-keratinizing (NK) type of carcinomas showed mixed variation in presentation being $10 \%$ of cases presenting with discharge $\mathrm{P} / \mathrm{V}$ with $20 \%$ cases presenting with stage I disease only [15].

Basaloid SCC is also a rare histologic variant with

Table 3. Correlation of Histopathologic Types with Stage of the Carcinoma Cervix

\begin{tabular}{lcc}
\hline Histologic type & Stage \\
& $\leq$ II & $\geq$ III \\
\hline SCC WD & 24 & 65 \\
ADWD & 6 & 4 \\
PD & 0 & 4 \\
UD & 1 & 1 \\
CCC & 0 & 1 \\
Total & 31 & 75 \\
\hline
\end{tabular}

poor prognosis and it was found in $0.94 \%$ of total cases. Due to its rarity much has not been studied about it. In our experience, age affected was $<49$ years, and clinical features were bleeding and discharge $\mathrm{P} / \mathrm{V}$ with clinical stage of IIB. No lymph node metastasis was detected except lymphovascular invasion [16].

$\mathrm{AD}$ of the cervix was seen in $14 \%$ of the cases, and presented in stage II and III. Discharge P/V was more commonly seen associated with $\mathrm{AD}$ than SCC and the recurrence rate was higher than SCC as seen in current analysis (7.1\%) [12-13]. As it is mentioned in the literature that there is no significant difference in the prognosis between $\mathrm{AD}$ and SCC. The prognostic significance of AD histology remains unclear [17-18]. As seen in our experience majority of the AD presents with classically endophytic growths (Figure 3) and tend to show deep infiltration of the cervix except in the cases where AD presented in the long standing endocervical polyps (Figure 4).

A timely and accurate diagnosis is the key to its successful management [14].

The papillary SCC of the cervix is also a rare variant of SCC. In our experience $2.9 \%$ of the cases were identified and presented with locally advanced disease. In the review of literature, papillary SCC is a disease of old aged and is a distinct type of carcinoma. Due to the indolent course of the variant, clinical presentation may vary and preoperative biopsy may be misleading due to pattern of growth both grossly as well as microscopically (Figure 5).

As seen in current study, no clinically visible growth or bleeding/ Discharge $\mathrm{P} / \mathrm{V}$ were seen except pain abdomen. Radiological findings suggested fibroid cervix. Histopathology revealed CIN III on preoperative biopsied and invasive papillary SCC was detected on hysterectomy

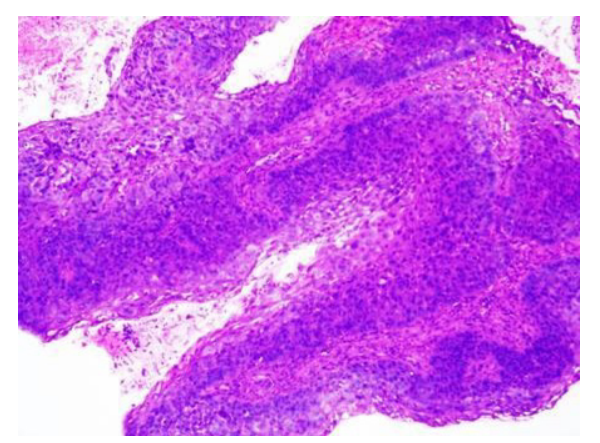

Figure 5. Papillary Squamous Cell Carcinoma Cervix (H\& E stained sections 20X) 
with invasion of deeper stroma upto paracervical tissue microscopically [19-20].

In this study the least common variant, a type of adenosquamous cell carcinoma (glassy cell carcinoma) was recognized accounting for $0.97 \%$ of total cervical carcinomas and presented with metastasis to solid organs. It is an aggressive tumour of the cervix accounting for $0.2 \%-9.3 \%$ of all uterine cervixes. This histologic type has the high incidence of early distant metastasis leading to fatal clinical outcome and minimal chances of survival, hence the treatment strategies are variable compared to the other subtypes [21]. Other least common types identified were neuroendocrine type $(1.8 \%)$ and undifferentiated type (1.9\%) [13-22]. The patients presenting with $\leq$ Stage II of carcinoma cervix responded well to treatment and showed good prognosis irrespective of type. However the patients with $\geq$ Stage III showed poor prognosis [23-24]. This study highlights a range of histopathological subtypes and variation in clinical presentation of carcinoma cervix in a small study population.

In conclusion, the current study stressed the fact that a majority of Indian women are diagnosed at later stages of cervical cancer rather than in its early treatable stages. There is a need for strengthening of screening programmes. Although clinical management and treatment of carcinoma cervix are not much relied upon a histopathological type and variants but there are many variants with different clinical presentations and specific light microscopic features which need to be considered clinically while dealing with unusual clinical presentations and supposed to be mentioned in the histopathology reports.

\section{References}

1. Mishra GA, Pimple SS, Shastri SS. Prevention of Cervix Cancer in India. Oncology. Epub. 2016;91:1-7.

2. Ferlay J, Soerjomatraram I, Dikshit R, Eser S, Mathers C, Rebelo $\mathrm{M}$ et al. Cancer incidence and mortality worldwide: Sources, methods and patterns in GLOBOCAN 2012. Int.J.Cancer. 2015;136:E359-86.

3. Denny L. Cervical cancer: prevention and treatment. Discov Med. 2012;14:125-31.

4. Gakidou E, Stella N, Ziad O. Coverage of cervical cancer screening in 57 countries:low average levels and large inequalities. PloS Med. 2009;5:e132.

5. Padubidri VG, Daftary SN. Shaw's Textbook of Gynecology. 15th ed. New Delhi: Elsevier; 2011

6. Zeller JL, Lynm C, Glass RM. Carcinoma of the cervix. JAMA. 2007;298:2336.

7. WHO/ICO. Human Papillomavirus and Related Cancers in India. Summary Report 2009. Information Centre on Human Papilloma Virus (HPV) and Cervical Cancer (a) 2009.

8. Aswathy S, Quereshi MA, Kurian B, Leelamoni K. Cervical cancer screening: current knowledge and practice among women in a rural population of Kerala, India. Indian J Med Res. 2012;136:205-10.

9. Sankaranarayanan R, Esmy PO, Rajkumar R, Muwonge R, Swaminathan R, Shanthakumari S et al. Effect of visual screening on cervical cancer incidence and mortality in Tamil Nadu: a cluster-randomized trial. Lancet. 2007;370:398-406.

10. Sharma A, Kulkarni V, Bhaskaran U, et al. Profile of cervical cancer patients attending Tertiary Care Hospitals of Mangalore, Karnataka: A 4 year retrospective study. Journal of Natural Science, Biology, and Medicine. 2017;8(1):12529.

11. Vallikad E. Cervical cancer: The Indian perspective. FIGO 26th annual report on the results of treatment in gynecological cancer. Int J Gynaecol Obstet. 2006;95(Suppl 1):S215-33.

12. Kaku M, Mathew A, Rajan B. Impact of socio-economic factors in delayed reporting and late-stage presentation among patients with cervix cancer in a major cancer hospital in South India. Asian Pac J Cancer Prev. 2008;9:589-94.

13. Mukhtar R, Mehmood R, Parveen SH, Mukhtar H. Prevalence of Cervical Cancer in Developing Country: Pakistan. Global Journal of Medical Research. 2015;15:12-7.

14. Ali F, Kuelker R, Wassie B. Understanding cervical cancer in the context of developing countries. Ann Trop Med Public Health. 2012;5:3-15.

15. Jin J. Screening for cervical cancer.JAMA. 2014 Dec 3;312(21):2302.

16. Kwon YS, Kim YM, Choi GW, Kim YT, Nam J-H. Pure Basaloid Squamous Cell Carcinoma of the Uterine Cervix: A Case Report. Journal of Korean Medical Science. 2009;24(3):542-5.

17. Fregnani JH, Soares FA, Novik PR, Lopes A, Latorre MR. Comparison of biological behavior between earlystage adenocarcinoma and squamous cell carcinoma of the uterine cervix. Eur J Obstet Gynecol Reprod Biol. 2008;136:215-23.

18. Kasamatsu T, Onda T, Sawada M, Kato T, Ikeda S, Sasajima Y, Tsuda H. Radical hysterectomy for FIGO stage I-IIB adenocarcinoma of the uterine cervix. Br J Cancer. 2009;100:1400-5.

19. Nagura M, Koshiyama M, Matsumura N, et al. Clinical approaches to treating papillary squamous cell carcinoma of the uterine cervix. BMC Cancer. 2014;14:784.

20. Odida M. Papillary squamous cell carcinoma of the cervix in Uganda: A report of 20 cases. African health sciences. 2005;5:291-4.

21. Guitarte C, Alagkiozidis J, Mize B, Stevens E, Salame G, Lee YiC. Glassy cell carcinoma of cervix: A systematic meta-analysis. GynecolOncol. 2014;133:186-91.

22. Tempfer, C. B., Tischoff, I., Dogan, A., Hilal, Z., Schultheis, B., Kern, P., \&Rezniczek, G. A. Neuroendocrine carcinoma of the cervix: a systematic review of the literature. BMC Cancer. 2018;18:530.

23. Horiot JC, Pigneux J, Pourquier H, Schraub S, Achille E, Keiling $\mathrm{R}$ et al. Radiotherapy alone in carcinoma of the intact uterine cervix according to G. H. Fletcher guidelines: a French cooperative study of 1383 cases. Int J Radiat Oncol Biol Phys. 1988;14:605-11.

24. Montana GS, Fowler WC, Varia MA, Walton LA, Mack Y, Shemanski L. Carcinoma of the cervix, stage III. Results of radiation therapy. Cancer. 1986;57:148-54.

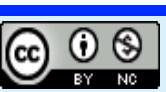

This work is licensed under a Creative Commons AttributionNon Commercial 4.0 International License. 